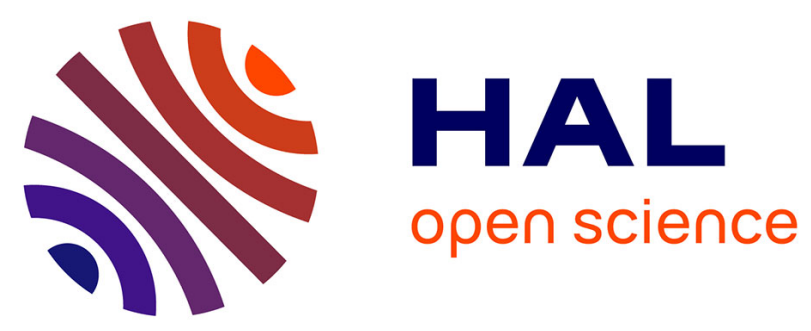

\title{
Evaluating And Measuring Knowledge Management's Impact On Supply Chain Performance Using HOQ
}

\author{
Fatma Lehyani, Alaeddine Zouari
}

\section{To cite this version:}

Fatma Lehyani, Alaeddine Zouari. Evaluating And Measuring Knowledge Management's Impact On Supply Chain Performance Using HOQ. IEEE SOLI 2015: 10th IEEE International Conference on Service Operations and Logistics, and Informatics, Nov 2015, Hammamet, Tunisia. hal-01893159

\section{HAL Id: hal-01893159 \\ https://hal.science/hal-01893159}

Submitted on 11 Oct 2018

HAL is a multi-disciplinary open access archive for the deposit and dissemination of scientific research documents, whether they are published or not. The documents may come from teaching and research institutions in France or abroad, or from public or private research centers.
L'archive ouverte pluridisciplinaire HAL, est destinée au dépôt et à la diffusion de documents scientifiques de niveau recherche, publiés ou non, émanant des établissements d'enseignement et de recherche français ou étrangers, des laboratoires publics ou privés. 


\section{Evaluating And Measuring Knowledge Management's Impact On Supply Chain Performance Using HOQ}

\author{
Fatma Lehyani* \\ Master Student STL - ISGI \\ UR LOGIQ \\ Sfax, Tunisia \\ fatmalehyani@gmail.com
}

\author{
Alaeddine Zouari \\ Dep. quality management - ISGI \\ UR LOGIQ \\ Sfax, Tunisia \\ Alaeddine.Zouari@isgis.rnu.tn
}

\begin{abstract}
Supply Chain Performance (SCP) depends on several factors additionally its length and the yield of its members. However, manage a Supply Chain (SC) means well managing knowledge as sharing them between actors involved in this process. Knowledge Management (KM) has, of appearance, a direct impact on SCP, but its formalization remains always ambiguous. In this context, this paper aims to determining the $\mathrm{KM}$ impact on the SCP through highlighting the relation between KM Elements (KME) and SCP Evaluation Criteria (SCPEC). Our approach consists, in the beginning, to position the knowledge concept in the SC through a conceptual model that identifies the KM impact on SCP based on mutual relations. Afterward, we adopt the House Of Quality (HOQ) to evaluate and measure the impact of each KME on whole SCPEC, similarly, the impact of whole KME on each SCPEC. An implementation example is proposed in the end.
\end{abstract}

Keywords-Supply Chain Performance, Performance Evaluation Criteria, Knowledge Management, Conceptual Model, House Of Quality (HOQ).

\section{INTRODUCTION}

Companies are often eager to look for a maximum performance level of their SC. This performance depends on the SC structure, as well as several elements appearing in this chain. Besides, it allows the company development and ensures a good brand image as well as a competitive advantage.

The SC and performance characteristics evolution generates a questioning on instrumentation and methods of piloting used until then. The definition and the setting-up of performance indicators raise numerous problems connected in particular to the performance notion evolution. Indeed, in this paper, we are going to study the performance notion, performance indicators, performance measurement, and finally criteria to measure this performance, etc. These elements have a strong relationship with knowledge and know how, in other words with knowledge acquired by the SC actors.

Nowadays, the KM has an important place in the economic and social environment. For this reason, many companies are looking to differentiate themselves with this new concept; therefore it became one of the primary objectives of each organization. These organizations must manage besides their financial, products and informational flows, their knowledge flow.

Any organization seeks to be reliable, efficient, agile, sustainable, etc. These criteria can't be achieved except with the effective KM. This management level allows it to excel on all levels because whoever manages well its knowledge, both explicit and implicit, can also wonderfully manage its resources without troubles or problems.

In the literature, there are several studies that have been developed to identify, for example, the KM impact on organization performance [30] or to show the effect of knowledge and information sharing on SC performance [29], etc. However, few works have studied the impact of KME on all criteria, influencing overall SC performance, or the extent of their impact.

The present work aims to evaluate and to measure the KM impact on SCP. Therefore, a conceptual model is proposed to clarify the relationship between $\mathrm{KME}$ and performance evaluation criteria and hence clearance of the KME impact on SCPEC. Moreover, we propose a methodology to measure the KME impact on overall SCPEC using the HOQ.

\section{Supply Chain Performance Evaluation CRITERIA}

\section{A. Concepts}

Alongside the traditional measure of productivity, other forms of performance have been gradually imposed. Induced by competitiveness, not only mono criterion based, (cost reduction), performance must nowadays be multi-criteria, taking into account different indicators to ensure the visibility and performance of all processes that interact in a SC. Several works on performance study concern the physical, financial and information flows [6].

Under the term "performance" there are three notions that are performance indicator, performance measurement and evaluation that we detail thereafter.

\section{1) Performance indicator}

The Key Performance Indicator (KPI) can be defined as indicator having a significant impact on the overall performance of an organization in the field of strategic, tactical 
and operational planning and control [7]. We distinguish various types of performance indicators which can be classified according to the performance nature: external or internal indicator.

In a general way, the indicator has sense only with regard to a piloted action. It is thus closely linked to a precise action process. It has to correspond to an objective and measures objective achievement (result indicator) or informs about the good progress of an action to reach this goal (piloting indicator). It is intended for use by specific actors.

\section{2) Performance Measurement}

The measure allows informing the performance affected by the system/process [2]. It is returned by the indicator and should reflect the real state, compared with the wished state (objective). The capacity to measure processes performance can be seen as an important prerequisite for the improvement. Companies have increased, during these last years, the possibilities offered by their performance measurement systems.

When measuring the SCP, it is important to place a company in terms of its maturity level given the variations, at different maturity levels, in the strategies interval to be adopted, setting organizational work and approaches used to measure performance [10].

\section{3) Performance evaluation}

Evaluation enriches the information given by a simple measure, and delivers an interpretation with regard to a global vision or a reference frame. Thus, contrary to the measure, which retains an important role but sticks to the effects, evaluation is more general: we try to go up the causes and also decide on the objectives and their implementation [22]. The evaluation is based on a model, either emulate the future system or to interpret the real system. This is not simply measuring the intrinsic value of objects but to establish a preference order.

The performance evaluation is used either to design a new system (or modify the existing system), or to control an existing system. In this context, several proposals of SCP evaluation process examples are proposed in the literature [23].

\section{B. SC Performance Evaluation Criteria}

In literature, the majority of authors often use the criteria of effectiveness, efficiency, reactivity and flexibility to estimate the SCP. In addition to these four basic criteria, we noticed the emergence of sustainability criteria on most recent publications of science community [17]. Besides, we noticed that in certain researches, authors introduce other performance criteria in a specific activity context in the SC such as: robustness [38], agility [39], profitability [13], productivity [13] and reliability [1].

Our vision consists in widening the application of these last criteria on all SC activities and in integrating them with the basic criteria. Nevertheless, we consider that the effectiveness criterion is integrated into the efficiency criterion and that the flexibility is a part of characteristics of the agility criterion [18]. Thereby, we conclude that the SCP depends on the following performance criteria: efficiency, reactivity, reliability, agility, productivity, robustness, profitability and sustainability, (Table 1).

TABle I. Supply ChAin PERFormance EVAluAtion CRITERIA

\begin{tabular}{|c|c|}
\hline Criteria & Definition \\
\hline Efficiency & Consists to make things right [40]. \\
\hline Reactivity & $\begin{array}{l}\text { It is the ability and responsiveness of steering faced with } \\
\text { an unexpected event, both endogenous as a machine } \\
\text { failure, and exogenous as a significant change in the order } \\
\text { book [14]. }\end{array}$ \\
\hline Reliability & $\begin{array}{l}\text { It is the probability of not having a malfunction during a } \\
\text { given time under given conditions. Such as, deliver the } \\
\text { right product at the right place at the right time from the } \\
\text { first time in compliance with specifications [15]. }\end{array}$ \\
\hline Agility & $\begin{array}{l}\text { It is the adaptability of processes, organizations and } \\
\text { supply chains that are sought to cope and develop in } \\
\text { unstable, turbulent, uncertain and risky environments [21]. }\end{array}$ \\
\hline Productivity & $\begin{array}{l}\text { The ratio between the production of a good or a service } \\
\text { and all the inputs required to produce it. It constitutes, in } \\
\text { fact, a measure of the effectiveness with which an } \\
\text { economy takes advantage of resources that it has to } \\
\text { produce goods or provide services. }\end{array}$ \\
\hline Robustness & $\begin{array}{l}\text { [37] describe a robust plan if and only if it provides low } \\
\text { dispersion of its characteristics despite the disruptive } \\
\text { fluctuations of uncontrollable factors. }\end{array}$ \\
\hline Profitability & $\begin{array}{l}\text { It is basically a discount rate whereas it is usually } \\
\text { measured as a ratio between income flows and capital } \\
\text { stock [28]. }\end{array}$ \\
\hline Sustainability & $\begin{array}{l}\text { The set of corporate sustainability strategies that are } \\
\text { dedicated to recognize both, the sustainability of the } \\
\text { market as well as social and environmental sustainability } \\
\text { [25]. }\end{array}$ \\
\hline
\end{tabular}

\section{KNOWLEDGE MANAGEMENT}

\section{A. Concept of knowledge}

For the Greek philosopher Platon, knowledge is what is necessarily true (episteme). On the other hand, the faith and the opinion ignore the reality of things, reason why they are within the framework of likely and the apparent.

The knowledge has its starting point in the sensory perception, then follows the understanding and ends finally on the reason. It is said that the knowledge is a relation between a subject, an object, an operation and a representation.

In the scientific literature, we find a large number of definitions relating to the knowledge concept. We illustrate some of them in table 2 .

\section{TABLE II. RELATIVE DEFINITIONS TO KNOWLEDGE}

\begin{tabular}{|c|l|}
\hline Author & \multicolumn{1}{c|}{ Knowledge Definition } \\
\hline$[9]$ & $\begin{array}{l}\text { The knowledge is a set of information (data set of } \\
\text { constraints type, rules, best practice, experiences) having } \\
\text { a sense to a person in a given context. }\end{array}$ \\
\hline$[24]$ & $\begin{array}{l}\text { The knowledge is seen as a process of decision, built } \\
\text { around two dimensions: the dimension of "the being", } \\
\text { which allows an individual to build his "world vision", } \\
\text { and the dimension of "doing", who allows an individual } \\
\text { to act on the world. }\end{array}$ \\
\hline$[35]$ & $\begin{array}{l}\text { The knowledge concerns the set of the knowledges and } \\
\text { the know-how mobilized by the actors within the } \\
\text { framework of their activities. knowledge is really } \\
\text { knowledge only if it is taken in the action and it has } \\
\text { senses only for those who produce it and for those use it. }\end{array}$ \\
\hline
\end{tabular}




\begin{tabular}{|c|l|}
\hline [8] & $\begin{array}{l}\text { The knowledge adds value to an organization through its } \\
\text { contribution to products, processes and people, while } \\
\text { KM transforms the information, data and intellectual } \\
\text { assets in sustainable value by identifying useful } \\
\text { knowledge for management actions. }\end{array}$ \\
\hline$[36]$ & $\begin{array}{l}\text { The knowledge is considered as the key factor of } \\
\text { company success, it is considered as the foundation of } \\
\text { the competitive advantage. it adds the value to an } \\
\text { organization by its contribution to products, processes } \\
\text { and people. }\end{array}$ \\
\hline
\end{tabular}

\section{B. Knowledge Management (KM)}

$\mathrm{KM}$ can be defined as "the generation, representation, storage, transfer, processing, application, rooting, and organizational knowledge protection. Organizational memory, information sharing and collaborative work are also closely related to KM concept". [32]

$\mathrm{KM}$ is not only a practice under the science philosophy guidance, but also a necessary requirement of globalization and knowledge-based society, further it is a process, in which the staff continuously transfer personal knowledge into organizational knowledge, and then increase individual knowledge through the organizational knowledge repository [20]. KM offers new insight for upgrading and transferring knowledge as well as practices within SC which helps in improving SCP in order to adopt KM effectively [26].

\section{Positioning Of Km On Supply Chain PeRformance}

Knowledge is the most important and critical factor of all resources that an enterprise manages for strategic Supply Chain Management (SCM) implementation [11]. Knowledge is the link between SC groups that work together in order to maintain an integrated and coordinated SC.

Therefore as a significant performance factor of the SC, Knowledge should have some properties for making successful SC decisions [5] namely:

- Knowledge should be accurate.

- Knowledge should be accessible when it is needed. The knowledge obtained after it is needed becomes invalid.

- Knowledge should be in the manner that it is needed. Useless and invalid knowledge should be eliminated.

- The knowledge cost should be of an acceptable level.

$\mathrm{KM}$ is a process through creation, accumulation, organization and knowledge use helps to achieve goals and to improve organizational performance [29]. It is clear that KM, that is a knowledge intensive activity, is significantly active in SCM. Knowledge is considered as the rivalry advantage source because it provides through its instantiation a share of commercial data and information in a controlled way. Also it helps to maintain an integrated and coordinated SC. Knowledge is the foundation stone of managerial decisions [27]. Despite the fact that sharing knowledge is important, its effect on SCP depends on which information is shared, when and how it is shared and with whom it is shared [19].

Knowledge share throughout the $\mathrm{SC}$ is a significant factor in today's global economy in SCP terms [3]. Knowledge also becomes the most important element for matching the supply and demand better, so that the SCP can be improved [12]. Moreover knowledge share is used as an important integration element for optimizing performance throughout the SC. [34]

However, knowledge sharing among groups of SC actors could accelerate the flow, increase efficiency and productivity, and provide quick access to necessary knowledge.

It is a sensitive approach to customer needs and a quick answer to altered customer needs. Thus knowledge share would gain a long term advantage in terms of rivalry for the organization [4], [33]. Business and academic worlds agree that rivalry advantage can be obtained by efficient KM [31].

\section{Modelling The Relation Between KME And SCPEC}

Several academic studies have attempted to identify the critical element of KM that influences mainly the SCP [16], [29]. However, our research approach aims to study simultaneously all KME influencing the overall SCP. In this context, we propose a conceptual model (Figure 1) that illustrates the relationships between KME and SCPEC.

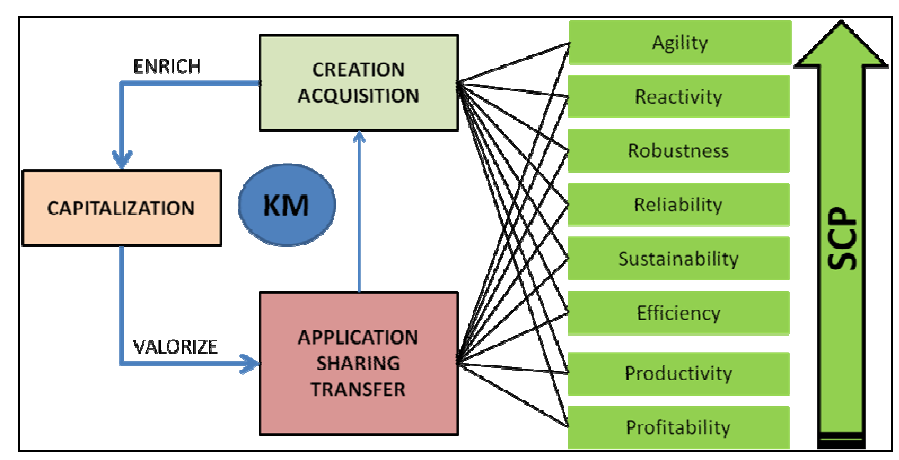

Fig. 1. Modeling the relationship between KME and SCPEC

We consider that KME are grouped under six main titles, namely: Acquisition, Transfer, Sharing, Creation, Capitalization and Application. However, SCPEC are grouped under eight titles that are: Reactivity, Reliability, Robustness Efficiency, Profitability, Productivity, Agility, and Sustainability (3RE2PAS).

- Knowledge acquisition: Knowledge is the main capital of modern companies, thus its capture is becomes a necessity as well as the internal skills development. The knowledge acquisition through the recourse to external experts allows to increase the knowledge repository and to improve the know-how development levels. It helps to enrich the skills, to provide training, to encourage integration and to favor learning. This new environment of movement, activity and improvement research leads to agility and reactivity.

- Knowledge transfer: It can manifest as an interaction between two people, a transfer between a person and a group of people or also an activity that takes place between two groups of people. This transfer must be intentional, with a clear desire to transfer knowledge to one or more recipients who are able to implement them. This means that in practice any knowledge transfer works only if the recipient integrates the message and 
applies it. However, the transfer requires an important commitment of actors and organizational support (infrastructure, animators, time clearances), but also it allows to become more sensitive and aware of customer expectations hence its fidelity moreover it increasing gain of market parts and afterward, the profitability improving.

- Knowledge sharing: It is a collective dimension where every person of product / service development team makes its contribution to the company intelligence and/or to the company memory. In a collaborative and concurrent environment, the exchange and the sharing must be voluntary and permanent. They must be made between the various levels of staff to allow the processing time minimization, the research, the check or the approval. This time gain allows the employees to have an extra time to produce furthermore. In fact, knowledge sharing in manufacturing companies allows fast and effective workflows so it supplies a special compromise between all actors, hence best productivity.

- Knowledge creation: It comes from the need and is linked to the brain faculty to adapt itself and to design. But all company actors are not equal in front of this creativity capacity. Thus, in the same business, knowhow is different from one person to another. To create a knowledge means being more active and more intelligent to solve problems and to overcome obstacles, that is also to be more strong in an unstable and disturbing environment, hence improving company robustness.

- Knowledge capitalization and application: Knowledge capitalization is action to extract, formalize and preserve the knowledge acquired and held in the daily practice of an activity, essentially the know-how and feedback. This is an activity that is approached using capitalization tools in order to retain and secure the company's memory (risk of knowledge loss). When knowledge security became among the first objective of an organization, it indicates that this organization has reached a fairly significant level of maturity and consciousness that allows it to last and resist face of market fluctuations and remain competitive in compared to competitors. Besides, the organization would be more reliable in customer's eyes. Once capitalized, knowledge application becomes simpler and easier. This application is an acceleration of knowledge natural transformation in use, use of versions, forms, comments, experiences, images, cases, etc. All of those pieces of knowledge are preserved by specific tools guaranteeing their re-use and enrichment, while optimizing time, effort and resources. That makes the organization effective, efficient and successful.

\section{Evaluation And MeAsure Of KME IMPACt On SCPEC USING HOQ}

Quality Function Deployment (QFD) is a structured method that uses the seven management and planning tools to identify and prioritize customers' expectations quickly and effectively.
Beginning with the initial matrix, commonly termed the HOQ, the QFD methodology focuses on the most important product or service attributes or qualities.

There are many different forms of the HOQ, but its ability to be adapted to the requirements of a particular problem makes it a very strong and reliable system to use. Its general format is made up of six major components. These include customer requirements, technical requirements, a planning matrix, an interrelationship matrix, a technical correlation matrix, a technical priorities/benchmarks and targets section.

Our approach consists in adapting HOQ to estimate the KME impact (considered as technical requirements) on whole SCPEC (considered as customer needs "the company itself for SCPEC"). Afterward, fill the matrix interrelation (needs / technical requirements) to determine the impact of each KME on all SCPEC under the form of a rate or a percentage. Similarly, it would be possible to determine the impact of all KME on each SCPEC.

Each SCPEC should have a priority weighting according to the company's eyes. This weighting is often qualitative varying between very strong to very weak and can be transformed into numbers using a predetermined evaluation grid with a scale of 1 to 9 or 1 to 5 etc.

The company can use different criteria for the SCPEC weighting such as their synergy with its policy and strategic objectives, by using a brainstorming or a weighted vote according to some predefined criteria (such as compatibility with the objectives, costs, the implementation deadline, available resources, etc.).

Further, it is necessary to fill the interaction matrix (SCPEC / KME) according to the impact's qualitative evaluation of each KME on every SCPEC that can go from very strong to very weak according to a predetermined grid.

The impact of each KME on all SCPEC will be determined by equation (1). In the same way, the impact of all the KME on every SCPEC will be determined by equation (2).

$$
I=\sum\left(S_{C P E C} * K M E_{j}\right) \quad(1), \quad J=S C P E C_{i} * \sum K M E_{j}
$$

To implement our approach, we propose to use SCPEC complementarity as weighting evaluation criterion.

A preliminary step consists in using an interaction grid (triangular matrix) between specific objectives of various SCPEC. This grid allows us to build a common goal for each binary combination of SCPEC. According to these objectives, we can identify those who are converging $(+)$, neutral (o) or diverging (-). Figure 2

To weight each SCPEC we have opted at the beginning to count number of times that SCPEC has been specified $(+),(0)$ and (-) with a respective coefficient (9), (3) and (1). Example for the SCPEC agility we have the sign $(+)$ and (o) twice and the sign (-) three times. The initial weighting will be:

$$
\text { Total }=2 * 9+2 * 3+3 * 1=27
$$


To use a scale of SCPEC weighting from 1 to 5, we consider frames in table 3 :

TABLE III. SCPEC WEIGHTING FRAMES

\begin{tabular}{|c|c|c|c|c|}
\hline $\mathbf{1 5} \leq \mathbf{T}<\mathbf{2 0}$ & $\mathbf{2 0} \leq \mathbf{T}<\mathbf{2 5}$ & $\mathbf{2 5} \leq \mathbf{T}<\mathbf{3 0}$ & $\mathbf{3 0} \leq \mathbf{T}<\mathbf{3 5}$ & $\mathbf{3 5} \leq \mathbf{T}<\mathbf{4 0}$ \\
\hline 1 & 2 & 3 & 4 & 5 \\
\hline
\end{tabular}

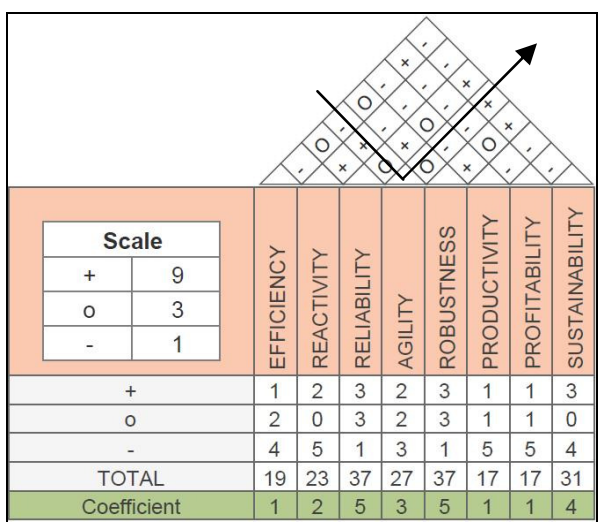

Fig. 2. Weighting SCPEC according to their complementarity

The second step consists in evaluating KME impact on each SCPEC. This evaluation is made in an intuitive way and based on our conceptual model and the reasoning at the level of the relations between those two concepts ( $c f$. V). The weighting will be in function of the impact intensity: strong (5), medium (3), weak (1).

The last step consists in calculating the relative impact of each KME on the SCPEC set and that of all the KME on each SCPEC.

\begin{tabular}{|c|c|c|c|c|c|c|c|c|c|}
\hline KME & 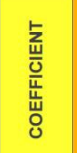 & $\begin{array}{l}\frac{0}{\alpha} \\
\frac{2}{\alpha} \\
\frac{\mathbf{s}}{\omega}\end{array}$ & 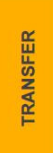 & 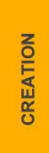 & 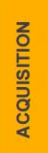 & $\begin{array}{l}z \\
\text { zo } \\
\frac{1}{2} \\
\frac{0}{1} \\
\frac{0}{0} \\
<\end{array}$ & 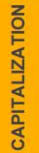 & $\frac{1}{\mathbb{5}}$ & ஃீ \\
\hline EFFICIENCY & 1 & 5 & 5 & 5 & & & 3 & 18 & 5,5 \\
\hline REACTIVITY & 2 & 3 & 5 & & 3 & 5 & 3 & 38 & 12 \\
\hline RELIABILITY & 5 & & & 5 & & & 5 & 50 & 15,5 \\
\hline AGILITY & 3 & 1 & 1 & & 3 & 5 & 5 & 45 & 14 \\
\hline ROBUSTNESS & 5 & 1 & 1 & 5 & 3 & & 5 & 75 & 23 \\
\hline PRODUCTIVITY & 1 & 5 & 3 & & 1 & 3 & & 12 & 4 \\
\hline PROFITABILITY & 1 & 3 & 5 & 5 & & 3 & 1 & 17 & 5 \\
\hline \multirow[t]{3}{*}{ SUSTAINABILITY } & 4 & 5 & 3 & & 3 & 1 & 5 & 68 & 21 \\
\hline & TOTAL & 47 & 43 & 60 & 43 & 35 & 95 & 323 & 100 \\
\hline & $\%$ & 14,5 & 13,5 & 18,5 & 13,5 & 11 & 29 & 100 & \\
\hline
\end{tabular}

Fig. 3. Evaluatng and measuring KME impact on SCPEC using HOQ

The HOQ results (Figure 3) relating to the application discussed above shows that knowledge capitalization is the most influential on all SCPEC (29\%), hence, company must focus on and well manage it to improve overall SCPEC. Similarly, we note that robustness criterion is the most affected by all KME $(23 \%)$, so any change in KME management will has a direct impact on the robustness criterion.

\section{CONCLUSION}

We conclude that KM has a direct impact on the SCP because every KME guaranteed one or several performance evaluation criteria. However, the efficient KM is recommended for an efficient SCM. Moreover, once the knowledge is correctly capitalized (categorized, saved, etc.), continuously enriched (acquisition and creation) and duly valued (applied / reused, shared and transferred), their impact is reflected in a significant minimization of errors and disturbances all throughout the SC. Consequently, companies have to affect the necessary importance for $\mathrm{KM}$ while managing their $\mathrm{SC}$ to achieve an optimal global performance, in other words guarantee that the company remains successful and competitive in front of the market fluctuations.

In future researches, we hope validate our model and methodology by their implementation within Tunisian companies, through a statistical study, to specify with a real case study, which KME are most critical and more sensitive to realize the SCPEC.

\section{ACKNOWLEDGMENT}

Authors would like to thank the respected anonymous reviewers for their valuable comments that greatly improve the paper's contribution.

\section{REFERENCES}

[1] C. E. Bauer, and H. J. Neuhaus, "Embedded packaging and assembly; Reliability and supply chain implications", Microelectronics Reliability, vol. 53, no 9, pp. 1179-1182, 2013.

[2] R. Benmoussa, and H. Laachir, "Mesure de la performance d'une chaîne logistique: méthode basée sur l'approche processus", CIGI'13, 11 au 14 juin 2013. La Rochelle, France.

[3] D.E. Cantor and J.R. Macdonald, "Decision making in the supply chain: examining problem solving approaches and information availability", Journal of Operations Management, vol. 27, no 3, p. 220-232, 2009.

[4] J.H. Cheng, C.H. Yeh and C.W. Tu, "Trust and knowledge sharing in green supply chains", Supply Chain Management: An International Journal, vol. 13, no 4, pp. 283-295, 2008.

[5] S. Chopra and P. Meindl, "Supply Chain Management. Strategy, Planning \& Operations", Pearson Prentice Hall, New Jersey, 3rd Edition, 2007.

[6] V. Humez, A. Amrani, M. Lauras and J.C. Deschamps., "SCMIP, Référentiel pour l'analyse de la performance de processus manipulant du flux d'information", 7th CIGI, Canada, 2005

[7] A. Gunasekaran, C.Patel, and R. E. Mc Gaughey, "A framework for supply chain performance measurement. International journal of production economics", vol. 87, no 3, pp. 333-347, 2004.

[8] A. Goh, "A strategic management framework for leveraging knowledge innovation", International Journal of the Computer, the Internet and Management, vol. 14, no 3, pp. 32-49, 2006.

[9] J.L. Ermine, "Les systèmes de connaissances", Paris, Edition Hermès, 2000.

[10] D. Estampe, S. Lamouri, J. L. Paris, and S. Brahim-Djelloul, "A framework for analysing supply chain performance evaluation models", International Journal of Production Economics, vol. 142, no 2, pp. 247$258,2013$.

[11] S.E. Fawcett, P. Osterhaus, G.M. Magnan, J.G. Brau and M.W. McCarter, "Information sharing and supply chain performance: the role of connectivity and willingness", Supply Chain Management: An International Journal; vol. 12, no 5, pp. 358-368, 2007. 
[12] Q. Fu and K. Zhu "Endogenous information acquisition in supply chain management", European Journal of Operational Research, vol. 201, no 2, p. 454-462 2010.

[13] J. Ju, \& X. Yu, "Productivity, profitability, production and export structures along the value chain in China", Journal of Comparative Economics. vol. 43, no 1, pp. 33-54, February 2015.

[14] F. Julien, "Planification des chaines logistiques : Modélisation du système décisionnel et performance", Thèse de Doctorat, Institut National des Sciences Appliquées de Lyon, 2007.

[15] T. Jouenne, "Les quatre leviers de la logistique durable", Revue Française de Gestion Industrielle, vol. 29, no1, pp. 1-24, 2010.

[16] S. Kanat, and T. Atilgan, "Effects of Knowledge Management on Supply Chain Management in the Clothing Sector: Turkish Case",.Fibres \& Textiles in Eastern Europe, vol.1, no 103, pp. 9-13,. 2014.

[17] P.R. Kleindorfer, K. Singhal and L.N. Van Wassenhove, "Sustainable operations management". Production and Operations Management vol $14 n^{\circ} 4$, pp. 482-492, 2005.

[18] F. Lehyani and A. Zouari "Towards modeling the supply chain's performance evaluation criteria", First International Conference on Transportation and Logistics, ICTL'2015, May 13 \& 14 2015, Sousse Tunisia.

[19] S. Li and B. Lin "Accessing information sharing and information quality in supply chain management", Decision Support Systems, vol. 42, no 3, p. 1641-1656, 2006.

[20] T. Liyanage, J. Kilbourne, A.P. Gerlich, and T.H. North, "Joint formation in dissimilar $\mathrm{Al}$ alloy/steel and $\mathrm{Mg}$ alloy/steel friction stir spot welds", Science and Technology of Welding \& joining, vol. 14, no 6, pp. 500-508, 2009.

[21] R. Mason-Jones, B. Naylor, and D. R. Towill, "Lean, agile or leagile? Matching your supply chain to the marketplace", International Journal of Production Research, vol. 38, no 17, pp. 4061-4070, 2000.

[22] A. Najmi, M.R. Gholamian and A. Makui "Supply chain performance models: A literature review on approaches, techniques, and criteria", Journal of Operations and Supply Chain Management, vol 6, $\mathrm{n}^{\circ} 2$, pp 94 $-113,2013$

[23] S. Nazemi, and A.S. Koloukhi, "Determining and Prioritizing Supply Chain Performance Evaluation Measures Using Lean Thinking Criteria". World of Sciences Journal, vol. 1, 2013.

[24] A. Pachulsky, "Le repérage des Connaissances cruciales pour l'entreprise : concepts, méthode et outils", Thèse, Université de Paris IX Dauphine, Paris, France, 2001.

[25] J. Parnell, "Sustainable strategic management: construct, parameters, research directions", International Journal of Sustainable Strategic Management, vol. 1, $\mathrm{n}^{\circ} 1$, pp. 35-45, 2008.

[26] S.K. Patil, and R. Kant, "A fuzzy AHP-TOPSIS framework for ranking the solutions of Knowledge Management adoption in Supply Chain to overcome its barriers". Expert Systems with Applications, vol. 41, no 2, pp. 679-693, 2014.

[27] J.V. Pereira, “The new supply chain's frontier: information management", International Journal of Information Management, vol. 29, no 5, p. 372-379. 2009.

[28] C. Picart, "Evaluer la rentabilité des sociétés non financières", Economie et statistique, vol.372, no 1, pp. 89-116, 2004.

[29] C. A. A. Rashed, A. Azeem, and Z. Halim, "Effect of information and knowledge sharing on supply chain performance: a survey based approach”,.Journal of Operations and Supply Chain Management, vol. 3, no 2, pp. 61-77, 2010.

[30] J. Rasula, V.B. Vuksic, and M.I. Stemberger, "The impact of knowledge management on organisational performance". Economic and Business Review for Central and South-Eastern Europe, vol. 14, no 2, p. 147, 2012.

[31] M. Sambasivan, S.P. Loke, and Z. Abidin Mohamed, "Impact of knowledge management in supply chain management: a study in Malaysian manufacturing companies". Knowledge and Process Management, vol. 16, no 3, pp. 111-123, 2009.

[32] U. Schultze, and D.E. Leidner, "Studying knowledge management in information systems research: discourses and theoretical assumptions" MIS quarterly, vol. 26 No. 3, pp. 213-242, September 2002.

[33] B. Sezen, "Relative effects of design, integration and information sharing on supply chain performance", Supply Chain Management: An International Journal, vol. 13, no 3, pp. 233-240, 2008.

[34] S. Titus and J. Bröchner, "Managing information flow in construction supply chains, Construction Innovation”, vol. 5, no 2, p. 71-82, 2005.

[35] T. Tounkara, "Gestion des Connaissances et Veille : vers un guide méthodologique pour améliorer la collecte d'informations", Thèse, Université de Paris IX Dauphine, Paris, France, 2002.

[36] S.M. Tseng, "A study on customer, supplier, and competitor knowledge using the knowledge chain model", International Journal of Information Management, vol. 29, no 5, pp. 488-496, 2009.

[37] H. Van Landeghem and H. Vanmaele, "Robust planning: a new paradigm for demand chain planning", Journal of Operations Management, vol. 20, no 6, pp. 769-783, Novembre 2002.

[38] T. Yang, , Y. F. Wen, and F. F. Wang, "Evaluation of robustness of supply chain information-sharing strategies using a hybrid Taguchi and multiple criteria decision-making method", International Journal of Production Economics, vol 134 no 2, pp. 458-466, 2011.

[39] Y. Y. Yusuf, A. Gunasekaran, A. Musa, M. Dauda, N. M. El-Berishy, and S. Cang, "A relational study of supply chain agility, competitiveness and business performance in the oil and gas industry", International Journal of Production Economics, no147, pp.531-543, 2014.

[40] K. Zokaei and P. Hines, "Achieving consumer focus in supply chains", International Journal of Physical Distribution \& Logistics Management, vol. 37, no 3, pp. 223-247, 2007. 